\title{
Growth and survival characteristics of Campylobacter jejuni in
}

\section{liquid egg}

\author{
BY M. L. HÄNNINEN,* H. KORKEALA* AND P. PAKKALA $\dagger$ \\ * College of Veterinary Medicine, Department of Food Hygiene, Hämeent. 57, \\ 00550, Helsinki 55, Finland, $\uparrow$ National Board of Health, Finland
}

(Received 10 August 1983; accepted 24 August 1983)

\section{SUMMARY}

Growth and survival of four Campylobacter jejuni strains in yolk, in liquid whole egg and in white during aerobic storage at 37,20 and $4{ }^{\circ} \mathrm{C}$ was followed. In $48 \mathrm{~h}$ at $37^{\circ} \mathrm{C}$ the cell counts of $C$. jejuni increased by about $3 \log _{10}$ units in yolk and $1 \cdot 60-3 \cdot 35_{10} \log$ units in liquid whole egg. The growth of $C$. jejuni was slightly better in yolk than in liquid whole egg. At $20^{\circ} \mathrm{C}$ during $48 \mathrm{~h}$ the cell counts decreased by about 0.5-1.5 $\log _{10}$ units in yolk and in liquid whole egg. At $4{ }^{\circ} \mathrm{C}$ the decrease in cell counts after 21 days ranged from 1 to $2 \log _{10}$ units, except for one strain, KH 3, which could not be detected after 14 days storage in yolk. In liquid whole egg the cell counts of this strain also decreased considerably during storage.

In white the number of inoculated $C$. jejuni cells decreased rapidly. The killing effect of white was shown to be temperature-dependent; at 37 and $20^{\circ} \mathrm{C}$ no positive samples were detected after $24 \mathrm{~h}$ and at $4{ }^{\circ} \mathrm{C}$ no positive samples were found after $48 \mathrm{~h}$.

\section{INTRODUCTION}

Human enteric disease caused by Campylobacter jejuni has a world-wide distribution (Skirrow, 1982). This infection has many characteristics in common with human salmonellosis; foods of animal origin, for example, are suspected to be important vehicles for the transmission of campylobacters to humans. Although there have not been many food-borne campylobacter epidemics reported, the importance of foods of animal origin in the epidemiology of this disease is based on the fact that many mammalian and avian species carry campylobacters as part of their intestinal flora. In particular, wild birds and poultry have been shown to form an important reservoir of C. jejuni (Grant, Richardson \& Bokkenheuser, 1980; Hänninen \& Raevuori, 1981 ; Kapperud \& Rosef, 1983), although it will be easier to evaluate the importance of these species in the epidemiology of human campylobacter infections after the distinctive characteristics of human pathogenic $C$. jejuni strains are known.

Liquid egg is widely used as a food ingredient at home, in food service establishments and in the food industry. Up to now salmonellas have been the only human pathogens transmitted via eggs to humans (Elliott \& Hobbs, 1980). Nowadays we can add to the list another pathogen, $C$. jejuni, which probably can also be transmitted via faecally contaminated eggshells to liquid egg. In most 
countries liquid egg products are pasteurized and thereafter stored either refrigerated or frozen. The pasteurization process probably destroys campylobacters as well as salmonellas, since the heat resistance of these organisms is roughly similar (Doyle \& Roman, 1981).

The purpose of the present study was evaluate the safety of liquid egg with respect to $C$. jejuni by following the growth of $C$. jejuni at $37^{\circ} \mathrm{C}$ and the survival of the organism at $20^{\circ} \mathrm{C}$ and at $4^{\circ} \mathrm{C}$ in yolk, in whole liquid egg and in white.

\section{MATERIALS AND METHODS}

\section{Bacterial strains and cultivation methods}

Four C. jejuni strains were used: NCTC 11168, KH 3, N 104 and L 41A, of human, bovine, and ovine origin, respectively. All strains were classified as C. jejuni according to Skirrow \& Benjamin (1980).

The strains were grown on plates of brucella agar (Difco) containing $5 \%$ blood and incubated at $42^{\circ} \mathrm{C}$ for $48 \mathrm{~h}$. One loopful of the growth on the blood agar plates was transferred into brucella broth supplemented with $0.05 \%$ each of sodium pyruvate, ferrous sulphate and sodium metabisulphite as recommended by Hoffman, Krieg \& Smibert (1979), and incubated at $42{ }^{\circ} \mathrm{C}$ for $24 \mathrm{~h}$. This growth was used as the inoculum in the experiments. The number of $C$. jejuni cells in the inoculum was counted by 10 -fold dilutions in $0.1 \%$ sterile peptone on brucella blood agar plates. The number of $C$. jejuni cells-in the liquid egg during storage was counted on a Skirrow-type medium (Hänninen \& Raevouri, 1981). All incubations were done microaerophilically $\left(5 \% \mathrm{O}_{2}+10 \% \mathrm{CO}_{2}+85 \% \mathrm{~N}_{2}\right)$ at $42{ }^{\circ} \mathrm{C}$.

\section{Survival of C. jejuni in liquid egg}

Fresh eggs were purchased, the shells were washed with soap and disinfected with ethanol, and the eggs were broken aseptically into sterile glass-jars. Three types of liquid egg samples were prepared: (1) whites; (2) yolks; (3) liquid whole eggs. For each treatment, $600 \mathrm{~g}$ of each type of liquid egg sample was inoculated with $6 \mathrm{ml}$ of 1:10 (vol./vol.) diluted campylobacter culture. The inoculum was mixed carefully into the liquid egg samples. The inoculated liquid egg samples were divided into $200 \mathrm{~g}$ portions, which were stored either at 37 , at 20 or at $4{ }^{\circ} \mathrm{C}$ in air in sterile glass bottles with tightly closed caps for $48 \mathrm{~h}, 48 \mathrm{~h}$ or 21 days, respectively. At the intervals desired, $10 \mathrm{~g}$ samples were taken from each product and serially diluted in sterile $0.1 \%$ peptone water; the colony-forming units of C. jejuni were then counted. Other microbiological analyses of the samples were counting of aerobic mesophilic bacteria (Plate-count Agar, Difco, incubated at $30^{\circ} \mathrm{C}$ for $72 \mathrm{~h}$ ) and coliform bacteria (Violet red bile agar, Difco, incubated at $35^{\circ} \mathrm{C}$ for $24 \mathrm{~h}$ ). The $\mathrm{pH}$ of the samples was also measured. Each campylobacter strain was examined twice under each condition.

\section{RESULTS}

At the beginning of the study, the $\mathrm{pH}$ of the yolk was 6.55 and the aerobic plate count ranged from $<\log _{10} 1$ to $\log _{10} 3 \cdot 1$. The corresponding values for liquid whole egg were $7 \cdot 70$ and $<\log _{10} 1-\log _{10} 4 \cdot 0$. The egg white was sterile and its $\mathrm{pH}$ was $9 \cdot 25$. No coliform bacteria were detected in any samples during the whole study period. 

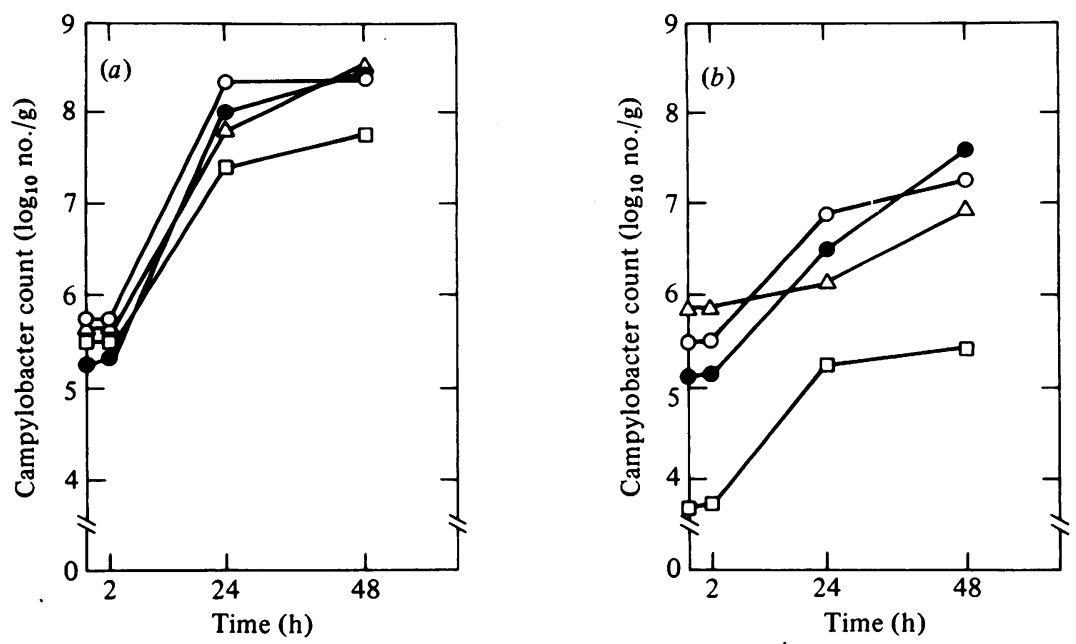

Fig. 1. Growth of $C$. jejuni in yolk (a) and in liquid whole egg $(b)$ at $37^{\circ} \mathrm{C}$. Strains and symbols used: NCTC $11168(O)$, N $104(O)$, L 41A $(\triangle)$, and KH $3(\square)$.
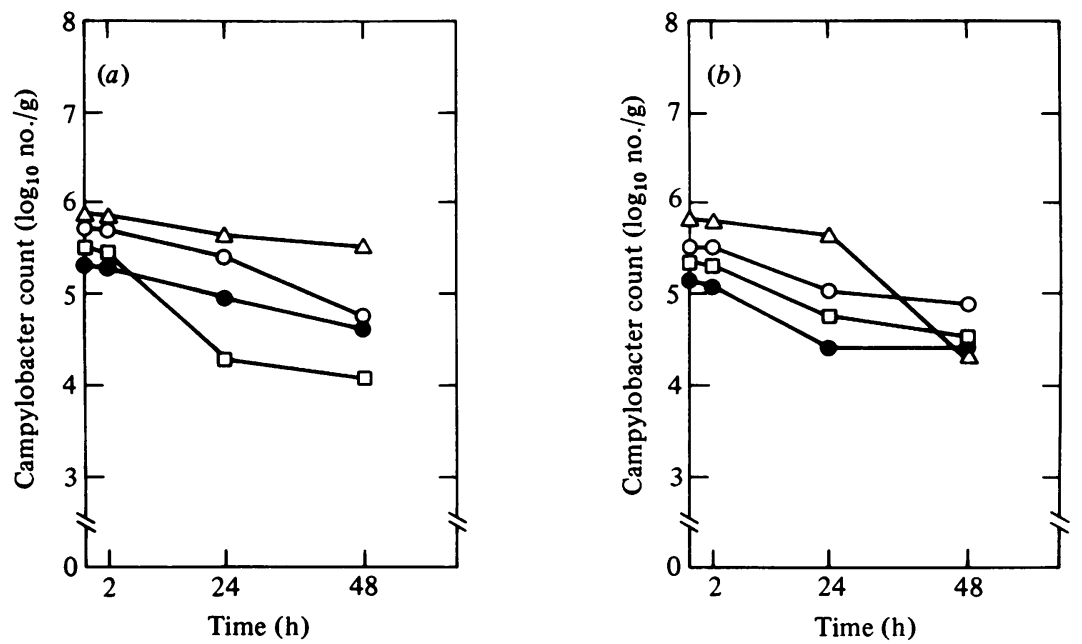

Fig. 2. Survival of $C$. jejuni in yolk $(a)$ and in liquid whole egg $(b)$ at $20^{\circ} \mathrm{C}$. Strains and symbols as in Fig. 1.

At $37^{\circ} \mathrm{C}$ the cell counts of all campylobacter strains increased during $48 \mathrm{~h}$ storage in air both in yolk and in liquid whole egg (Fig. 1). The increase in the campylobacter cell counts was approximately $3 \log _{10}$ units in yolk and from 1.60 to $3.35 \log _{10}$ units in liquid whole egg. No great differences in the growth rate of campylobacter strains were noted at this temperature. In the yolk samples taken after $48 \mathrm{~h}$, the $\mathrm{pH}$ value ranged from 6.30 to 6.65 and the aerobic plate count from $<\log _{10} 1$ to $\log _{10} 8.5$. A high or low aerobic plate count in the samples did not seem to have any effect on campylobacter counts. The corresponding values in liquid whole egg ranged from 7.70 to $7 \cdot 85$ and from $<\log _{10} 1$ to $\log _{10} 8 \cdot 0$. Egg white was inhibitory to all $C$. jejuni strains. The counts of $C$. jejuni decreased considerably during $4 \mathrm{~h}$ incubation at $37^{\circ} \mathrm{C}$ and in the samples taken after $24 \mathrm{~h}$ incubation no C. jejuni cells could be detected. 

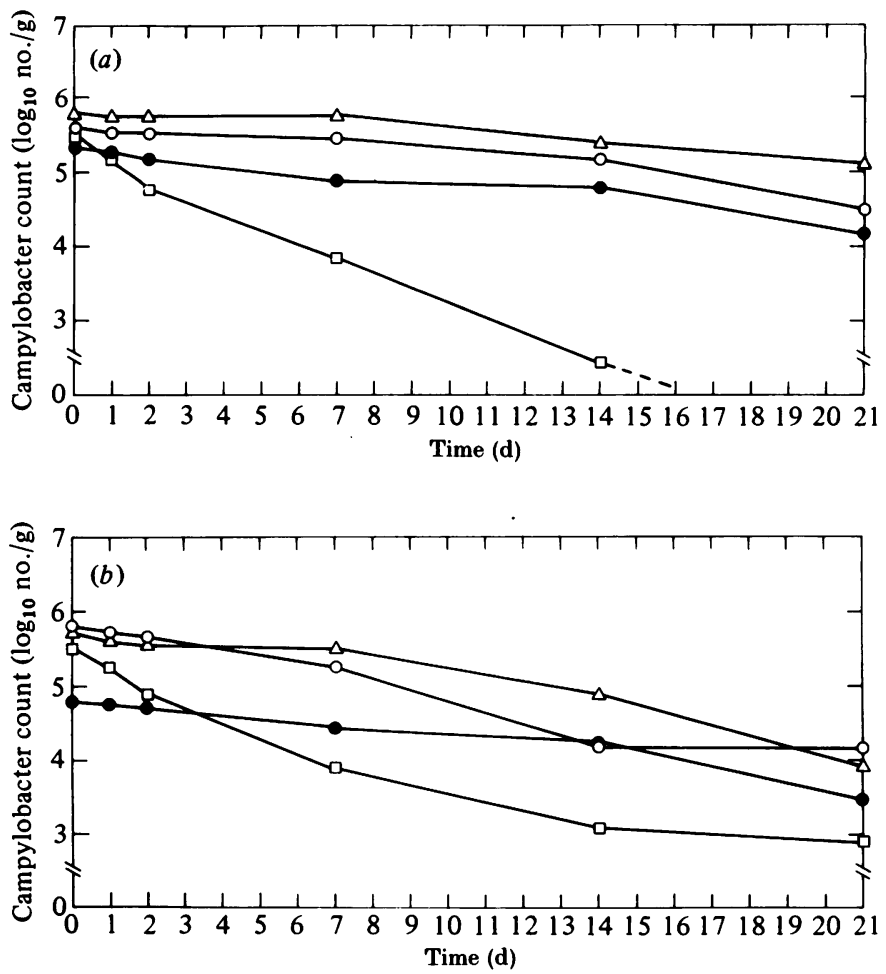

Fig. 3. Survival of $C$. jejuni in yolk $(a)$ and in liquid whole egg $(b)$ at $4^{\circ} \mathrm{C}$. Strains and symbols as in Fig. 1.

At $20^{\circ} \mathrm{C}$ the counts of inoculated $C$. jejuni cells decreased by about $0.5-1.5 \log _{10}$ units both in yolk and in liquid whole egg during $48 \mathrm{~h}$ (Fig. 2). After $48 \mathrm{~h}$, no noteworthy differences in the cell counts between strains were noted. After incubation, the aerobic plate counts ranged from $<\log _{10} 1$ to $\log _{10} 8 \cdot 0$, the $\mathrm{pH}$ value of the yolk was 6.5 and that of the liquid whole egg $7 \cdot 75$. In white a rapid decrease in campylobacter cell counts occurred during $4 \mathrm{~h}$ storage and no campylobacter cells were detectable after $24 \mathrm{~h}$. The $\mathrm{pH}$ value of the white after incubation was 9.30.

At $4{ }^{\circ} \mathrm{C}$ the campylobacter cell counts decreased during 21 days storage $1-2 \log _{10}$ units in yolk and by approximately $1 \log _{10}$ unit in whole liquid egg (Fig. 3). Strain KH 3 was different from the other strains studied. After 14 days storage it was not detectable in yolk, and also in liquid whole egg its counts decreased during the total storage period by about $2.5 \log _{10}$ units. After storage, the aerobic plate counts ranged in both samples from $<\log _{10} 1$ to $\log _{10} 7 \cdot 0$. In white the counts of C. jejuni decreased rapidly during $24 \mathrm{~h}$ storage and after $48 \mathrm{~h}$ storage no positive samples were detected.

\section{DISCUSSION}

The present study showed that in foods rich in nutrients, which have a suitable environment, such as egg yolk and liquid whole egg, $C$. jejuni can grow in air. 
Aerobic growth of $C$. jejuni has formerly been obtained in a cultivation medium by adding superoxide anion quenching chemicals to the medium (Hoffman et al. 1979), on red meat (Gill \& Harris, 1982), and in sterile ground chicken meat (Blankenship \& Craven, 1981), but not, for example, in milk (Christopher, Smith \& Vanderzant, 1982). Egg yolk contains proteins and lipids, and its iron content is relatively high (Board, 1969). Yolk has been shown to improve the recovery of bacterial cells after various environmental stresses by destroying toxic compounds in the recovery medium (Baird-Parker, 1965). The semifluid consistency of yolk and liquid whole egg and the protective capacity of yolk against toxic forms of oxygen are probably important factors in controlling the growth of $C$. jejuni in these foodstuffs stored in air. The $\mathrm{pH}$ values of yolk and whole liquid egg are favourable for the growth of $C$. jejuni.

Egg white contains numerous antimicrobial systems, such as lysozyme and conalbumin, which chelates iron, copper and zinc; it also has an alkaline $\mathrm{pH}$ and a low nutrient content (Boad, 1969). In the present study $C$. jejuni was shown to be rapidly killed in white. The phenomenon was temperature-dependent; at 37 and $20^{\circ} \mathrm{C}$ the cells were destroyed more rapidly than at refrigeration temperature. Other gram-negative organisms, such as salmonellas, have also been shown to be effectively destroyed in white, although when the $\mathrm{pH}$ of white was adjusted to 7-8 they grew well (Banwart \& Ayres, 1957). The relative importance of the various antimicrobial factors present in egg white was not analysed in the present study. The high $\mathrm{pH}$ value of white was probably not the most important factor in the inhibition of growth or survival of the organism, since certain C. jejuni strains have been shown to grow in a cultivation medium at pH 9.5 (Doyle \& Roman, 1981). When the white and yolk are mixed the antimicrobial properties of white are lost (Elliott \& Hobbs, 1980). This was also found in the present study at all temperatures used. However, the growth of $C$. jejuni was slightly better in yolk than in the whole liquid egg.

In many countries, liquid egg products are pasteurized and thereafter stored either frozen or refrigerated. Pasteurized liquid egg has a remarkably long refrigerated shelf-life, 20-22 days (Kraft et al. 1967). The present study showed that $C$. jejuni will survive in liquid egg at least as long as the shelf-life of these products. The survival of $C$. jejuni in yolk and in liquid whole egg, both at 20 and at $4{ }^{\circ} \mathrm{C}$, was roughly the same as that observed earlier in meat (Christopher et al. 1982 ), or on meat (Gill \& Harris, 1982). With respect to the survival of $C$. jejuni at refrigerated temperature, there are probably differences between strains; in the present study one $C$. jejuni strain was shown to be more sensitive to refrigerated storage than the other three strains. Survival at 20 or at $4{ }^{\circ} \mathrm{C}$ in the present test conditions in yolk and in liquid whole egg was not shown to be temperaturedependent, as has been found to be the case in many other milieus, including milk, water, urine and faeces (Blaser et al. 1980) or on meat (Gill \& Harris, 1982); the decrease in the cell counts during two first days of storage was almost the same at 4 and at $20^{\circ} \mathrm{C}$.

This work was financially supported by National Board of Health, Finland. 


\section{REFERENCES}

BAIRD-PARKer, A. C. (1965). The effect of recovery medium on the isolation of Staphylococcus aureus after heat treatment and after storage of frozen or dried cells. Journal of Applied Bacteriology 28, 390-402.

Banwart, G. J. \& Ayres, J. C. (1957). The effect of $\mathrm{pH}$ on the growth of Salmonella and functional properties of liquid egg white. Food Technology 11, 244-246.

Blank enship, I. C. \& Craven, S. E. (1982). Campylobacter jejuni. Survival in chicken meat as a function of temperature. Applied and Environmental Microbiology 44, 88-92.

Blaser, M. J., Hardesty, H. L., Powers, B. \& Wang, W. L. (1980). Survival of Campylobacter fetus subsp. jejuni in biological milieus. Journal of Clinical Microbiology 11, 309-313.

BoARd, R. G. (1969). Microbiology of the hen'segg. Advances in Applied Microbiology 11, 245-281.

Christopher, F. M., Smith, G. C. \& VANDerzant, C. (1982). Effect of temperature and pH on the survival of Campylobacter fetus. Journal of Food Protection 45, 253-259.

Doyle, M. P. \& Roman, D. J. (1981). Growth and survival of Campylobacter fetus subsp. jejuni as a function of temperature and pH. Journal of Food Protection 44, 596-601.

Elliotr, R. P. \& Hoвbs, B. C. (1980). Eggs and egg products. In Microbial Ecology of Foods. Vol. 2. Food Commodities, ICMSF, pp. 521-566. New York: Academic Press.

GILL, C. O. \& HaRRIs, L. M. (1982). Survival and growth of Campylobacter fetus subsp. jejuni on meat and in cooked foods. Applied and Environmental Microbiology 44, 259-263.

Grant, I. H., Richardson, N. J. \& Bokkenheuser, V. D. (1980). Boiler chickens as potential source of Campylobacter infections in humans. Journal of Clinical Microbiology 11, 508-510.

Hoffman, P. S., KRIEG, N. R. \& Smibert, R. M. (1979). Studies of the microaerophilic nature of Campylobacter fetus subsp. jejuni. I. Physiological aspects of enhanced aero- tolerance. Canadian Journal of Microbiology 25, 1-7.

HäNnINEN, M. L. \& RAEVUORI, M. (1981). Occurrence of Campylobacter fetus subsp. jejuni and Yersinia enterocolitica in domestic animals and in some foods of animal origin in Finland. Nordisk Veterinär Medicin 33, 441-445.

KAPPERUD, G. \& Roser, O. (1983). Avian wildlife reservoir of Campylobacter fetus subsp. jejuni, Yersinia spp. and Salmonella spp. in Norway. Applied and Environmental Microbiology 45, 375-380.

Kraft, A. A., Ayres, J. C., Forsythe, H. R. \& Schultz, J. R. (1967). Keeping quality of pasteurized liquid egg yolk. Poultry Science 46, 1282.

Skirrow, M. B. (1982). Campylobacter enteritis - the first five years. Journal of Hygiene, 89, 175-184.

Skirrow, M. B. \& Benjamin, J. (1980). Differentiation of enteropathogenic campylobacter. Journal of Clinical Pathology 33, 1122. 